$$
\text { CONF- } 961123 \cdots 3
$$

Long Term Instability in the Defect Assembly in Irradiated High Resistivity Silicon Detectors*

V. Eremin, A. Ivanov, E. Verbitskaya

Ioffe-Physico-Technical Institute of Russian Academy of Sciences 194021 St. Petersburg, Russia

\title{
Z. Li
}

Brookhaven National Laboratory

Upton, NY 11973-5000

\section{B. Schmidt}

Institute for Ion Beams and Material Research

Research Center Rossendorf, D-01314 Dresden, Germany

May, 1996

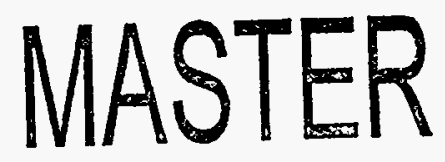

*This research was supported in part by the U. S. Department of Energy: Contract No. DE-AC02-76CH00016. 


\section{DISCLAIMER}

Portions of this document may be illegible in electronic image products. Images are produced from the best available original document. 


\section{DISCLAIMER}

This report was prepared as an account of work sponsored by an agency of the United States Government. Neither the United States Government nor any agency thereof, nor any of their employees, makes any warranty, express or implied, or assumes any legal liability or responsibility for the accuracy, completeness, or usefulness of any information, apparatus, product, or process disclosed, or represents that its use would not infringe privately owned rights. Reference herein to any specific commercial product, process, or service by trade name, trademark, manufacturer, or otherwise does not necessarily constitute or imply its endorsement, recommendation, or favoring by the United States Government or any agency thereof. The views and opinions of authors expressed herein do not necessarily state or reflect those of the United States Government or any agency thereof. 
Long term instability in the defect assembly in irradiated high resistivity silicon detectors

\author{
V.Eremin, A.Ivanov, and E.Verbitskaya \\ Ioffe Physico-Technical Institute of Russian Academy of Sciences, \\ 194021 St-Petersburg, Russia \\ Z.Li \\ Brookhaven National Laboratory, \\ Upton, New York 11973, USA \\ B.Schmidt \\ Institute for Ion Beams and Material Research, \\ Research Center Rossendorf, D-01314 Dresden, Germany
}

\section{Abstract}

Different kinetic behévior has been revealed for the two types of irradiated high resistivity silicon detectors in the reactions of the interstitial carbon $\left(C_{i}\right)$ annealing and the formation of the $C_{i-}$ $\mathrm{O}_{\mathrm{i}}$ complex. In the detectors with an increased oxygen contents prolonged growth of the $\mathrm{C}_{\mathrm{i}}-\mathrm{O}_{\mathrm{i}}$ complex concentration obeyed the second order reaction due to an additional source of $\mathrm{C}_{\mathrm{i}}$ atoms which were not detected by DLTS measurements. Transformation of carbon related defects has been analyzed concerning the long term instability of irradiated silicon detectors.

\section{Introduction}

The problem of reverse annealing of irradiated silicon detectors has been studied in details in its macroscopic evolution [1,2]. The data showed accumulation of the negative charge in the space charge region which resulted in the increase of the net effective concentration $N_{\text {eff }}$ [3]. Hypotheses available to explain this phenomenon are based on microscopic reactions with various dominant defects. This paper presents the results concerning instability of radiation induced defects in high resistivity silicon detectors which originates from the reactions with carbon related defects.

\section{Experimental procedure}

Detectors used in the study were made from $n$ type FZ Si with resistivities of $\rho=1-2 \mathrm{k} \Omega-\mathrm{cm}$ (Freiberger Elektronikwerkstoffe GmbH) and of $5 \mathrm{k} \Omega-\mathrm{cm}$ (Wacker Chemitronic). Irradiation was made by $\alpha$-particles or neutrons followed by annealing at RT or elevated temperatures. The spectra of radiation induced defects were measured by C-DLTS technique.
3. Kinetic behavior of carbon related defects

The investigation was concentrated on the processes with carbon related defects: annealing of the interstitial carbon $\mathrm{C}_{i}, \mathrm{Hl}=\mathrm{E}_{\mathrm{y}}+0.33 \mathrm{eV}$, and simulteneous formation of the $\mathrm{C}_{\mathrm{i}}-\mathrm{O}_{\mathrm{i}}$ complex, $\mathrm{H} 2$ $=E_{\mathrm{y}}+0.40 \mathrm{eV}$, Annealing of the $\mathrm{C}_{\mathrm{i}}$ atoms with a concentration $n_{x}(t)$ obeyed the first order reaction:

$$
n_{x}(t)=n_{x 0} \exp (-t / \tau)
$$

where $\tau$ is the time constant. The kinetic parameters of this reaction have been revealed to depend on the oxygen contents introduced during thermal oxidation [4]. According to these parameters the detectors were devided into two groups: 1) "fast" samples with an increased oxygen contents ( $\tau$ was found to be several hours at RT); 2) "slow" samples with a lower oxygen contents (similar values of $\tau$ were achieved at $\sim 50^{\circ} \mathrm{C}$ ). In defect studies [5], the concentration of neutron induced defect level with an activation energy $E_{\mathrm{a}}=$ $0.39 \mathrm{eV}$ conrelated with the reverse annealing of

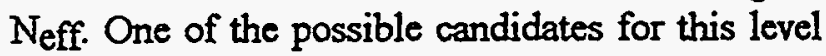
can be the $\mathrm{C}_{\mathrm{i}}-\mathrm{O}_{\mathrm{i}}$ complex.

Formation of the $\mathrm{C}_{\mathrm{i}}-\mathrm{O}_{\mathrm{i}}$ complex with a concentration $N_{x}(t)$ may be described as the first order reaction:

$$
N_{x}(t)=n_{x 0}[1-\exp (-t / \tau)]
$$

if it is controlled by the $C_{i}$ concentration solely, or may obey the second order reaction of the two components $\mathrm{C}_{\mathrm{i}}$ and $\mathrm{O}_{\mathrm{i}}$ with similar concentrations:

$$
N_{x}(t)=n_{x 0}\left(1-\frac{1}{1+k n_{x 0} t}\right)
$$

where $k$ is the rate constant of the reaction.

The isothermal annealing data for the $\mathrm{Hl}$ and H2 centers for "fast" sample (Wacker Si) showed that even after the total exhsustion of the interstitial 
carbon (during $\sim 15$ hours) the concentration of the $\mathrm{C}_{\mathrm{i}}-\mathrm{O}_{\mathrm{i}}$ center has been observed to its trend of increase even at RT (Fig.1). Under prolonged annealing ( -40 days) the best fit of the data could be obtained using the second order reaction. The constant $k \sim 10^{-17} \mathrm{~cm}^{3} \mathrm{~s}^{-1}$ was similar to the rate constant of $N_{\text {eff }}$ reverse annealing in [2].

The difference in the kinetic behavior of the $\mathrm{C}_{\mathrm{i}}$ defect and the $\mathrm{C}_{\mathrm{i}}-\mathrm{O}_{\mathfrak{i}}$ complex implies that the $\mathrm{C}_{\mathrm{i}}-\mathrm{O}_{\mathrm{i}}$ complex formation may be controlled by an additional process of carbon and oxygen atom interaction. An "excessive" concentration of the $\mathrm{C}_{\mathrm{i}}-\mathrm{O}_{\mathrm{i}}$ complex $N_{\alpha c}$ was defined as:

$$
N_{e c c}=N_{x}-N_{s i n}^{1}
$$

where $N_{s i m}^{1}$ is the concentration simulated according eq.(1) with the parameters $n_{x 0}$ and $\tau$ corresponding to the $C_{i}$ annealing. The best fit of the excessive concentration can be obtained with the second order reaction (Fig.2), similar to the total concentration of the $\mathrm{C}_{\mathrm{i}}-\mathrm{O}_{\mathrm{i}}$ complex. After the second irradiation the concentration increase of the $\mathrm{C}_{\mathrm{i}}-\mathrm{O}_{\mathrm{i}}$ complex showed two stages: an initial fast concentration increase during the first 25 hours of RT anneal fitted by the second order reaction, and efterwards the saturation of the concentration.

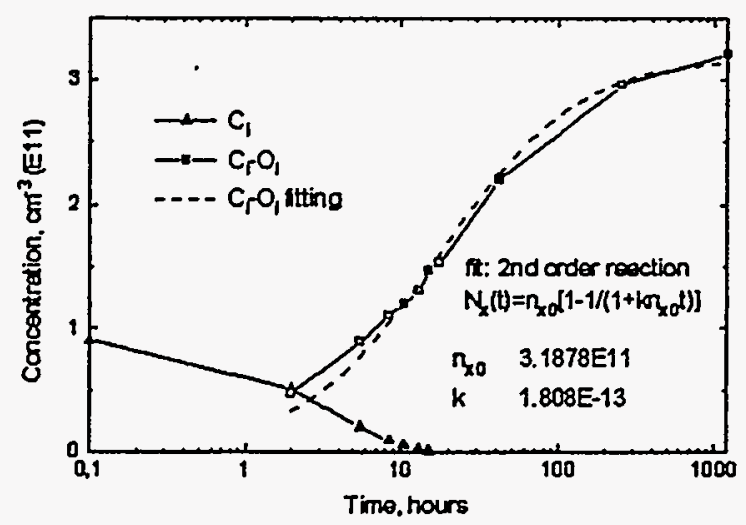

Fig.1. Isothermal RT annealing of the interstitial carbon and the $\mathrm{C}_{\mathrm{i}}-\mathrm{O}_{\mathrm{i}}$ complex.

For "slow" samples, the increase of the concentration of the $\mathrm{C}_{\mathrm{i}}-\mathrm{O}_{\mathrm{i}}$ complex correlated well with the $\mathrm{C}_{\mathrm{i}}$ decay which occurred during $\sim 30$ hours at $\mathrm{T}=50^{\circ} \mathrm{C}$.

\section{Discussion}

For both types of the detectors the second order reaction for the formation of the $\mathrm{C}_{\mathrm{i}}-\mathrm{O}_{\mathrm{i}}$ complex is observed at least after the first irradiation-annealing cycle. Hence, the two components $\mathrm{C}_{\mathrm{i}}$ and $\mathrm{O}_{\mathrm{i}}$ with similar concentrations are assumed to combine in the defect formation.

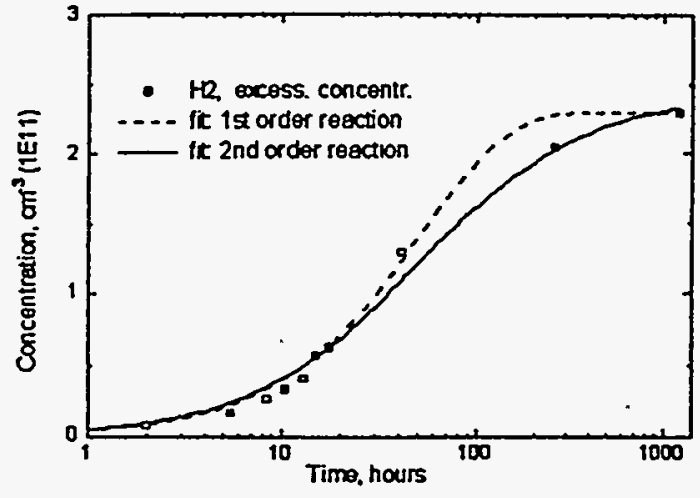

Fig.2. RT annealing of the "excessive" concentration of the $\mathrm{C}_{\mathrm{i}}-\mathrm{O}_{\mathrm{i}}$ complex.

Further, significant increase of the concentration of the $\mathrm{C}_{\mathrm{i}}-\mathrm{O}_{\mathrm{i}}$ complex after the exhaustion of the interstitial carbon implies an additional source of this constituent in the $\mathrm{C}_{\mathrm{i}}-\mathrm{O}_{\mathrm{i}}$ complex generation. This additional source may also explain the fact that after the second irradiation-annealing cycle the saturation concentration of the $\mathrm{C}_{\mathrm{i}}-\mathrm{O}_{\mathrm{i}}$ complex exceeded that after the first irradiation-annealing cycle. These atoms together with electrically active $\mathrm{C}_{\mathrm{i}}$ centers measured by DLTS may have participated in the generation of the $\mathrm{C}_{\mathrm{i}}-\mathrm{O}_{\mathrm{i}}$ complex and presumbly dominate in the "fast" samples.

We assume that accumulation of the $\mathrm{C}_{\mathrm{i}}-\mathrm{O}_{\mathrm{i}}$ complex may affect the reverse annealing only in the very early stage of the $\mathrm{N}_{\text {eff }}$ change. Still, the data on isochronous elevated temperature annealing show concentration increase only for carbon related defects. Thus, the results give rise to suggest that instability in the defect assembly in irradiated silicon detector can arise from the complexes including carbon and oxygen.

\section{References}

1. Z.Li, W.Chen, L.Dou, V.Eremin, H.W.Kraner, C.J.Li, G.Lindstroem, and E.Spiriti. IEEE Trans. Nucl. Sci., NS-42, 219 (1995).

2. H.Feick, E.Fretwrist, S.Kanitz, G.Lindstroem, K.H.Mahlmann, G.Meyer, and T.Schulz. IEEE Trans. Nucl. Sci., NS-42, 387 (1995).

3. Z.Li, C.J.Li, V.Eremin, E.Verbitskaya. Preprint BNL-61334, Nucl. Instr. \& Meth A (in press).

4. B.Schmidt, V.Eremin, A.Ivanov, N.Strokan, E.Verbitskaya, and Z.Li. J.Appl.Phys. 76, 4072 (1994).

5. Z.Li, C.J.Li, V.Eremin, and E.Verbitskaya. Preprint BNL-61687, IEEE Trans. Nucl.Sci. (in press). 